\title{
A Risk Metric for Educational Informatization Project Based on Information Entropy
}

\author{
Tang Mingjing ${ }^{1,2}$, Liao Hongzhi ${ }^{2}$, Li Jinxu ${ }^{3}$ and Gan Jianhou ${ }^{4+}$ \\ ${ }^{1}$ President Office, Yunnan Normal University, Kunming, Yunnan province, China \\ ${ }^{2}$ School of Software, Yunnan University, Kunming, Yunnan province, China \\ ${ }^{3}$ School of Information Science and Technology, Kunming, Yunnan province, China \\ ${ }^{4}$ Key Laboratory of Educational Informatization for Nationalities, Ministry of Education, Kunming, Yunnan \\ Province, China
}

\begin{abstract}
Education informatization is an important means of education reform and innovation by means of the information technology. There are a large number of risk factors in the process of education informationization project establishment, construction and management which can contribute to project failure. Based on the related research results and characteristics of education informatization, this paper provides a quantificational risk measurement model based on information entropy, and verify this model by five different types of project data. The verification results show that this method can effectively measure education informationization project risk.
\end{abstract}

Keywords: information entropy, risk metric, educational informatization

\section{Introduction}

Education informatization is the process of improving and innovating education by the information and communication technologies. The development of education informatization will expand the channels of education, realizing high quality education resources sharing, improving the quality of education, and promoting the education fairness [1]. In recent years, education informatization has become a key focus of national, local, school and education institutions at all levels, the number and funds investment of education informatization construction project is increasing annually, and has greatly promoted the development of education informatization. These education informatization construction projects have made remarkable achievements in the course resource sharing, teaching mode innovation, personnel training and so on. However, some problems in the process of education informatization project management are exposed, such as the demand is not clear, the lack of long-term planning, insufficient funds continued support, personnel training does not reach the designated position, the lack of policy support, and so on [2]. The root causes of these problems are that the works of risk identification, measurement, assessment and avoiding were not well done in the process of education informatization project construction and management.

Informatization project risk are those negative factors that hindering the project and the loss caused by those factors. At present, informatization risk assessment and measurement have been studied extensively, but the focus, the range of application and method of these researches are varied. Baccarini D et al. [3] analysed and summarized 27 important risk factors of informatization construction project, then classified and sorted for these risk factors. Wang [4] identified and analysed the risk of university informatization, established indicator system and model framework of risk evaluation in university informatization construction. In view of the software project, Yang [5] constructed a software project risk

${ }^{+}$Corresponding author. Tel.: + 86(0871-65911456); fax: +86(0871-65911001).

E-mail address: tmj@ynnu.edu.cn. 
identification system based on nine knowledge areas of project management, evaluated software project risk based on fuzzy evaluation method, improved the subjective data of the risk assessment model based on the expert evaluation method and the Monte Carlo Simulation, and evaluated overall risk of software project by using comprehensive risk coefficient. In general, the project risk research considering the characteristics of education informatization is less. Most of these researches are qualitative researches which the probability and impact of project risk is assessed and analysed, these is a lack of quantitative researches which quantitative analysis the impact of risk on the overall goal. The education informatization project risk metric is to early identify project risks and accurately measure the risk loss, then effectively reduce or avoid the risk loss, and improve the success rate of education informatization construction projects. This paper presents a quantitative risk metric method of education informatization project based information entropy, according to the characters of education informatization.

\section{Analysis and Definition of Education Informatization Project}

\subsection{Analysis of Education Informatization Project}

Education informatization project not only has the common features of general information project, also has its own industry characteristics. Such as huge funds investment and long investment period, pursuit of social benefits rather than economic benefits, easy affected by the policy, personalized demands and complex internal management, and so on. Therefore, it is need to combine the industry characteristics of education informatization in risk analysis and assessment. This paper provides eight risk factors and level division of education informatization project, which based on the work of Qian [6] and real situation of education informatization project. As shown in Table 1.

Table 1: Risk Factor and Level Division

\begin{tabular}{|c|c|c|c|}
\hline No. & Risk Factor & Risk Level & Score \\
\hline \multirow[t]{5}{*}{$\mathrm{R} 1$} & \multirow[t]{5}{*}{ Organization risk } & Higher: no support and participate, the budget is not reasonable & 0.9 \\
\hline & & High: a little support and participate, the budget is a little reasonable Normal: normal & 0.7 \\
\hline & & support and participate, the budget is normal reasonable & 0.5 \\
\hline & & Low: more support and participate, the budget is more reasonable & 0.3 \\
\hline & & Lower: most support and participate, the budget is most reasonable & 0.1 \\
\hline \multirow[t]{5}{*}{$\mathrm{R} 2$} & \multirow[t]{5}{*}{ Human resource risk } & Higher: staff level, technical skills, participation do not meet the requirements & 0.9 \\
\hline & & High: staff level, technical skills, participation rarely meet the requirements & 0.7 \\
\hline & & Normal: staff level, technical skills, participation basically meet the requirements & 0.5 \\
\hline & & Low: staff level, technical skills, participation meet the requirements & 0.3 \\
\hline & & Lower: staff level, technical skills, participation more meet the requirements & 0.1 \\
\hline \multirow[t]{5}{*}{ R3 } & \multirow[t]{5}{*}{ User side risk } & Higher: the user information literacy is lower, very resistant to change & 0.9 \\
\hline & & High: the user information literacy is low, less resistant to change & 0.7 \\
\hline & & Normal: the user information literacy is average, no resistant to change & 0.5 \\
\hline & & Low: the user information literacy is high, can accept change & 0.3 \\
\hline & & Lower: the user information literacy is higher, more accept change & 0.1 \\
\hline \multirow[t]{5}{*}{$\mathrm{R} 4$} & \multirow[t]{5}{*}{ Infrastructure risk } & Higher: lack of basic infrastructure and network equipment, cannot reform & 0.9 \\
\hline & & High: a few of basic infrastructure and network equipment, reform difficult & 0.7 \\
\hline & & Normal: basic infrastructure and network equipment meet demand, normal reform & 0.5 \\
\hline & & Low: enough basic infrastructure and network equipment, normal reform & 0.3 \\
\hline & & Lower: have high-end equipment, easy reform & 0.1 \\
\hline \multirow[t]{5}{*}{ R5 } & \multirow[t]{5}{*}{ Information resource risk } & Higher: unable to get information resources & 0.9 \\
\hline & & High: information resources are old and less & 0.7 \\
\hline & & Normal: information resources are meet basic requirements & 0.5 \\
\hline & & Low: information resources are enough & 0.3 \\
\hline & & Lower: a huge number of information resources & 0.1 \\
\hline \multirow[t]{5}{*}{ R6 } & \multirow[t]{5}{*}{ Information system risk } & Higher: do not conform to the goal, do not have extensibility & 0.9 \\
\hline & & High: basic conform to the goal, do not have extensibility & 0.7 \\
\hline & & Normal: can conform to the goal, have a little extensibility & 0.5 \\
\hline & & Low: more conform to the goal, have more extensibility & 0.3 \\
\hline & & Lower: very conform to the goal, have most extensibility & 0.1 \\
\hline \multirow[t]{4}{*}{$\mathrm{R} 7$} & \multirow[t]{4}{*}{ Policies risk } & Higher: do not meet the target of the country, do not meet the various standards & 0.9 \\
\hline & & High: basic meet the target of the country, do not meet the various standards & 0.7 \\
\hline & & Normal: meet the target of the country, basic meet the various standards & 0.5 \\
\hline & & Low: more meet the target of the country, meet the various standards & 0.3 \\
\hline
\end{tabular}




\begin{tabular}{llll}
\hline & Lower: most meet the target of the country, most the various standards & 0.1 \\
\hline R8 & Technical risk & Higher: changes frequently, do not conform to the standard, is immature & 0.9 \\
& & High: less changes, basic conform to the standard, little immature & 0.7 \\
& Normal: no changes, conform to the standard, basic mature & 0.5 \\
& Low: stabilization, conform to the standard, more mature & 0.3 \\
& Lower: stabilization, conform to the standard, most mature \\
\hline
\end{tabular}

\subsection{Definition of Education Informatization Project}

The probability and loss of risk factors are two important characteristics of education informatization project risk. Thus, the education informatization project risk can be defined as a triple $=(\mathrm{S}, \mathrm{P}, \mathrm{L})$. The $\mathrm{S}$ is education informatization project risk factors set, the $\mathrm{P}$ is the probability of risk factors, the $\mathrm{L}$ is the loss caused by risk factors [7].

\section{Education Informatization Project Risk Metric Model Based on Information Entropy}

\subsection{Theory Analysis of the Information Entropy}

The concept of entropy is derived from physics, its physical meaning is measurement of system chaotic degree. In 1948, the founder of information theory, Shannon extended the concept of entropy to the information field, and established the information entropy. The information entropy established a quantitative method about uncertainty, and laid the theoretical basis of modern information theory. The definition is as follows:

Suppose the system have $n$ possible state: $\mathrm{X}_{1}, \mathrm{X}_{2}, \cdots, \mathrm{X}_{\mathrm{n}}$, the probability of each state are $\mathrm{P}_{1}, \mathrm{P}_{2}, \cdots, \mathrm{P}_{\mathrm{n}}$, and $0<\mathrm{P}_{\mathrm{i}} \leq 1(i=1,2, \cdots, n), \sum_{i=1}^{n} P_{i}=1$, then the information entropy of the system is: $\mathrm{H}\left(\mathrm{P}_{1}, \mathrm{P}_{2}, \cdots, \mathrm{P}_{\mathrm{n}},\right)=-\mathrm{k} \sum_{i=1}^{n} P_{i} \ln P_{i}(\mathrm{k}$ is ratio). Due to the uncertainty is the basic characteristic of risk, and the information entropy can effectively measure uncertainty of system. Therefore, the information entropy can be used to measure the risk. The order degree of system is higher, the entropy value, uncertainty and the risk is smaller. The order degree of system is lower, the entropy value, uncertainty and the risk is greater.

\subsection{Analysis of the Risk Metric Model}

Education informatization project risk measurement should consider not only the probability of risk factors, but also the loss of risk factors on the project. As a result, the education informatization project risk can be defined as the product of the risk factors probability and the risk loss.

Assume that education informatization project have $\mathrm{n}$ risk factors: $\mathrm{X}_{1}, \mathrm{X}_{2}, \cdots, \mathrm{X}_{\mathrm{n}}$, the probability of each risk factor are: $\mathrm{P}_{1}, \mathrm{P}_{2}, \cdots, \mathrm{P}_{\mathrm{n}},\left(0<P_{i} \leq 1\right)$, the risk loss are: $L_{1}, L_{2}, \cdots, L_{n}\left(0<\mathrm{Li}_{i} \leq 1\right)$, therefore, the education informatization project risk influence are: $A_{1}, A_{2}, \cdots, A_{n}, A_{i}=\sqrt{P_{i} L_{i}}, i=1, \cdots, n\left(0<A_{i} \leq 1\right)$. After normalizing the $\mathrm{A}_{\mathrm{i}}$, then:

$$
\mathrm{p}_{i}=\frac{A_{i}}{\sum_{j=1}^{n} A_{j}}, i=1, \cdots, n \text { and } 0<\mathrm{p}_{i} \leq 1, \sum_{i=1}^{n} p_{i}=1
$$

From the above risk definition and the information entropy theory, the education informatization project risk metric model is as follows:

$$
R=-\sum_{i=1}^{n} A_{i} \frac{p_{i} \log _{2} p_{i}}{\log _{2 n}}, \text { and } 0<R \leq 1
$$

\section{The Example Analysis and Verification}

Based on the work of Pan [8] and the work experience in the education informatization of the research team, this paper should measure risk of five different types of education informatization project. Those projects involve in software project, network integrated wiring project, servers and storage project, network 
security project and IT operations management project, and so on. The probability of risk factors and loss degree are as follows:

$$
\begin{aligned}
P & =\left\lfloor\begin{array}{cccccccc}
0.2 & 0.35 & 0.6 & 0.3 & 0.5 & 0.7 & 0.55 & 0.1 \\
0.75 & 0.2 & 0.5 & 0.4 & 0.8 & 0.6 & 0.4 & 0.2 \\
0.5 & 0.8 & 0.75 & 0.9 & 0.3 & 0.6 & 0.8 & 0.4 \\
0.1 & 0.4 & 0.2 & 0.1 & 0.6 & 0.2 & 0.5 & 0.3 \\
0.4 & 0.7 & 0.4 & 0.5 & 0.2 & 0.6 & 0.1 & 0.5
\end{array}\right] \\
\mathrm{L} & =\left\lfloor\begin{array}{cccccccc}
0.7 & 0.55 & 0.2 & 0.4 & 0.5 & 0.2 & 0.3 & 0.6 \\
0.4 & 0.5 & 0.7 & 0.2 & 0.3 & 0.1 & 0.9 & 0.4 \\
0.9 & 0.6 & 0.8 & 0.7 & 0.7 & 0.5 & 0.8 & 0.7 \\
0.5 & 0.7 & 0.4 & 0.2 & 0.5 & 0.1 & 0.1 & 0.2 \\
0.7 & 0.2 & 0.5 & 0.3 & 0.2 & 0.6 & 0.75 & 0.4
\end{array}\right]
\end{aligned}
$$

The matrix $\mathrm{P}$ refer to the probabilities of risk factors in the education informatization project, the matrix $\mathrm{L}$ refer to the losses caused by risk factors in the education informatization project. The risk affect matrix A for these five education informatization projects are as follows:

$$
A=\left|\begin{array}{cccccccc}
0.3742 & 0.4387 & 0.3464 & 0.3464 & 0.5 & 0.3742 & 0.4062 & 0.2449 \\
0.5477 & 0.3162 & 0.5916 & 0.2828 & 0.4899 & 0.2449 & 0.6 & 0.2828 \\
0.6708 & 0.6928 & 0.7746 & 0.7937 & 0.4583 & 0.5477 & 0.8 & 0.5292 \\
0.2236 & 0.5292 & 0.2828 & 0.1414 & 0.5477 & 0.1414 & 0.2236 & 0.2449 \\
0.5292 & 0.3742 & 0.4472 & 0.3873 & 0.2 & 0.6 & 0.2739 & 0.4472
\end{array}\right|
$$

Then, the $\rho$ matrix is as follow:

$$
\rho=\left|\begin{array}{cccccccc}
0.1235 & 0.1447 & 0.1143 & 0.1143 & 0.165 & 0.1235 & 0.134 & 0.0808 \\
0.1632 & 0.0942 & 0.1763 & 0.0843 & 0.146 & 0.073 & 0.1788 & 0.0843 \\
0.1274 & 0.1315 & 0.1471 & 0.1507 & 0.087 & 0.104 & 0.1519 & 0.1005 \\
0.0958 & 0.2267 & 0.1211 & 0.0606 & 0.2346 & 0.0606 & 0.0958 & 0.1049 \\
0.1624 & 0.1148 & 0.1372 & 0.1188 & 0.0614 & 0.1841 & 0.084 & 0.1372
\end{array}\right|
$$

Accordingly, the five different types of education informatization project's risk can be calculated according to the project risk metric model, they are: $0.3826,0.4331,0.6652,0.3095,0.4179$.

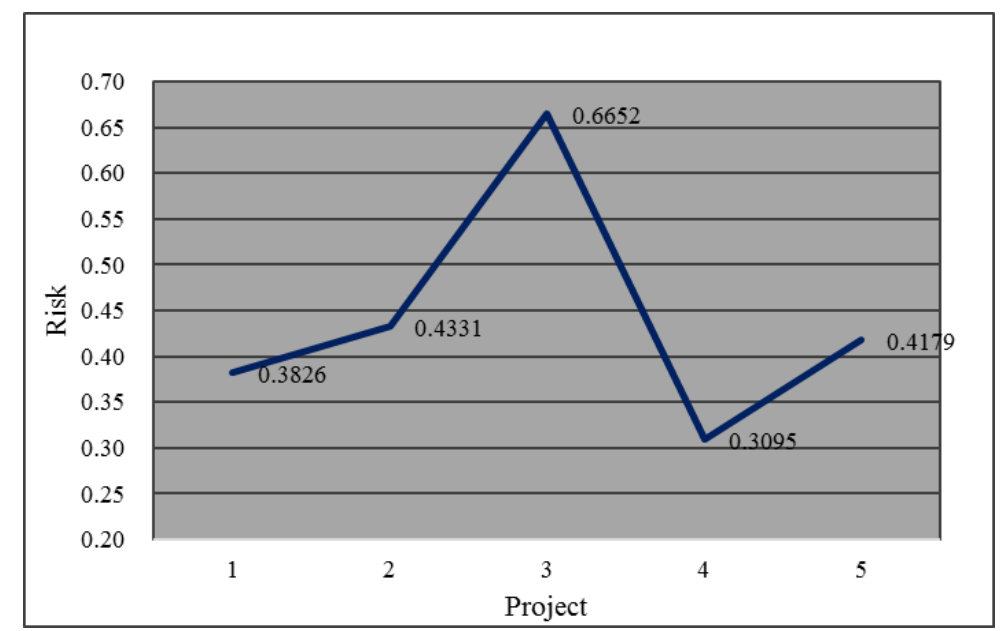

Fig. 1: The project and risk. 
Figure 1 indicate that the risk of the third project is greatest, the risk of the fourth project is minimal. Actual situation shows that the third project is a software project which involving significant process reengineering and deep business integration, it is difficult to implement, therefore, it's risk is greatest. The fourth project is a hardware equipment deployment project which only involving technology risk and can be controlled, therefore, it's risk is minimal.

Compared to others study, there are some advantages in the proposed model in this paper. Firstly, this is a quantitative risk research method. The risk of education informatization project can be calculated via formulas above and its result is more objective, which avoids subjective estimation. Then, this paper quantitative analyzed and refined the risk measurement in education informatization project based on the multiple levels. Therefore, it is benefit for targeted management and maintenance, and avoid project risk to a great extent.

\section{Conclusions}

At present, project quantity is becoming more and more, the capital investment is becoming greater and greater in the education informatization construction. But, a standardized solution has not yet been established which involving project risk identification, risk assessment, risk measurement and risk avoidance in the education informatization. This paper established an education informatization project risk metric model based on the relevant research results and information entropy. Then the model was verified with the data from five different types education informatization project. The verification result show that the risk metric method is correct and effective.

\section{Acknowledgements}

This work was supported by National Natural Science Foundation of China (Grant No. 61562093), Key Project of Applied Basic Research Program of Yunnan Province of China (Grant No. 2016FA024), Natural Science Foundation of the Department of Education of Yunnan Province of China(Grant No. 2017ZZX073).

\section{References}

[1] Jiao Jianli, Jia Yimin, Ren Gaimei. Research on Macro Policies and Strategies of Educational Informatization. Journal of distance education. 2014(1):25-32.

[2] Zhang Chenjingzi, Wang Ying, Wang Xiaodong, Jiao Jianli, Zhang Yinghua. A Policy Comparison, Development Tendency and Enlightenment of Education Informatization Evaluation. Journal of Distance Education. 2015(4):22-33.

[3] Baccarini D, Salm G, Love P E D. Management of risks in information technology projects. Industrial Management \& Data Systems, 2004, 104(4):286-295.

[4] Wang Qi. The university informatization construction risk assessment research. Diss. Harbin Engineering University, 2012.

[5] Yang Jing. Study on Risk Recognition and Assessment Models of Software Project. Diss. Southeast University, 2006.

[6] Qian Dongming, Wang Juan, Xu Xianlong. Research on Risk Management of ICT Projects in Education. Research in Education Development, 2016(Z1):23-28.

[7] Jiang Rong, Liao Hongzhi, Zhang Xinming, Zeng Zhiyong. Model of Measuring Software Development Risk Based on Information Entropy. Microcomputer Its Applications, 2009, 28(13):71-72.

[8] Pan Meisen, Yan Junyan. Software Project Risk Evaluation Model Based on Learning Vector Quantization. Computer Engineering and Applications, 2006, 42(12):126-130. 